\title{
NUEVAS FORMAS DE FAMILIA, VIEJAS POLÍTICAS FAMILIARES. LAS FAMILIAS MONOMARENTALES
}

\author{
Susana Ruiz Seisdedos ${ }^{1}$ \\ María del Carmen Martín Cano ${ }^{2}$ \\ Universidad de Jaén
}

\begin{abstract}
Resumen: En los últimos años la familia tradicional, formada por una pareja heterosexual casada, con o sin descendencia y con los roles de género claramente marcados, ha dejado paso a nuevos modelos de familia, como son matrimonios del mismo sexo, familias recompuestas, familias monoparentales, etc. El objetivo de este artículo es poner de manifiesto este cambio en las relaciones personales y familiares que se está produciendo en España, tomando como referencia uno de los cambios más significativos experimentados últimamente respecto a los modelos familiares: las familias monomarentales, así como las dificultades que deben salvar a pesar de estar amparadas por normativas de igualdad.
\end{abstract}

Palabras clave: modelos familiares, familias monomarentales, políticas sociales de apoyo a las familias.

\section{New models of family, old family policies. The single mothers}

Abstract: In the last years the traditional family formed by a heterosexual married pair, with or without descent and with the roles of kind clearly marked, has opened way for new models of family, since they are marriages of the same sex, recompound families, single-parent families, etc. The aim of this article is to reveal this change in the personal and familiar relations that one is producing in Spain, taking as it indexes one of the most significant changes experienced lately with regard to the familiar models: the families monomarenales, as well as the difficulties that they must save in spite of being protected by regulations of equality.

Keywords: familiar models, families monomarentales, social policies of support to the families.

\footnotetext{
${ }^{1}$ Profesora Titular de Universidad. Área de Ciencia Política y de la Administración. Universidad de Jaén. suruiz@ujaen.es

${ }_{2}^{2}$ Diplomada en Trabajo Social. Máster en Dependencia e Igualdad en la Autonomía Personal. Doctoranda en Ciencias Sociales y Jurídicas. Universidad de Jaén. mc-martin@hotmail.com
} 


\section{Introducción}

En las líneas que a continuación se presenta se pretende poner de manifiesto una realidad poco conocida aunque cada día más usual, el cambio en las relaciones personales y familiares en España. Nuestro país se ha convertido en poco tiempo en uno de los más aventajados a la hora de ampliar derechos a una parte de la población, permitiendo el matrimonio entre parejas del mismo sexo y ampliándoles, por tanto, la posibilidad de tener hijos, ya sean estos adoptados o biológicos mediante técnicas de reproducción asistida.

Por tanto, a pesar de la importancia de la familia, lo cierto es que en las última década la familia tradicional, formada por una pareja heterosexual casada, con o sin descendencia y con los roles de género claramente marcados, ha dejado paso a nuevos modelos de familia. Claramente estamos asistiendo a un cambio social que ha tenido su base en la esfera privada de las personas, relacionada con sus actitudes, con sus hábitos y con su modo de entender la convivencia. Nos encontramos ante una realidad social, familiar y personal fruto del cambio social.

El artículo que se presenta pretende ser una primera aproximación a esta realidad: los nuevos modelos familiares, al margen del modelo nuclear, poniendo especialmente el acento en las familias monoparentales -o monomarentales, en cuanto mayoritariamente están compuestas por la madre y sus hijos e hijas-. Asimismo, se analizarán las distintas políticas sociales existentes de apoyo para las familias y la posible discriminación de la familia monomarental en relación con la tradicional.

\subsection{Estado del bienestar familista en España.}

Para entender las políticas de apoyo a la familia existente en España, se observa como necesario conocer cuál es nuestro sistema de bienestar social y cómo se configura pues muchas de las grietas del mismo son consecuencia de los principios sobre los que se asienta el mismo.

España se configura según la ampliamente utilizada categorización de EspingAndersen (2000) como un estado social continental en el que el principio del mérito en el mercado es un medio básico para gestionar las políticas sociales. Frente al principio de necesidad y sin abandonar el mismo, lo fundamental se basa en las prestaciones contributivas que las personas hacen al mercado. Dentro de este modelo, los estados del Sur de Europa formarían parte del submodelo conocido como Estado familista, según el cual las políticas públicas dan por supuesto que las familias deben asumir la provisión de bienestar a sus miembros (Kasza, 2002).

Probablemente la mayor aportación que se ha realizado desde los países mediterráneos, como crítica a los Estados de Bienestar, haya sido el concepto de "familismo", entendido como "una confianza permanente en la familia, en su solidaridad intergeneracional y en su estructura tradicional de género, como proveedora de trabajo y servicios asistenciales y como integradora de medidas inadecuadas de apoyo a los ingresos" (Saraceno, C. 2004).

Siguiendo el análisis de Esping-Andersen (2000), el régimen de bienestar socialdemócrata ha conseguido un elevado grado de desfamiliarización debido 
al apoyo dado a la masiva integración de la mujer en el mercado laboral, mientras que el régimen de bienestar conservador se caracteriza por la permanencia del modelo de varón sustentador y por la dependencia familiar de la mujer.

En este contexto analítico, los países del sur de Europa se incluyen en la categoría del régimen conservador. Estas referencias parecen señalar que en dichos países existe cierta interdependencia entre el régimen de bienestar, el régimen laboral y el modelo de relaciones familiares y de género. En la misma línea investigadores como Goodin et al. (2000) y Muffels et al. (2002) hablan del "Southern model of the labour market" caracterizado entre otros aspectos por la reducida participación laboral de la mujer.

Por tanto, a la hora de buscar alternativas a nuestro Estado de Bienestar (Santiso, R: 2000), es importante considerar la situación y perspectiva de las mujeres ya que éstas, además de suponer la mitad de los miembros de una sociedad, son las que principalmente sufren parte de las consecuencias de las crisis y quienes cargan también, de modo invisible y poco reconocido, con parte de su resolución. El papel del Estado de Bienestar y las políticas que elabore en esta dirección resultarán decisivos para posibilitar un cambio de conciencia social así como la articulación y flexibilización de distintas tareas y opciones en la vida de las personas (Martín y Ruiz, 2010).

Contrariamente a lo que pudiera parecer se trata de un modelo en el que las ayudas y políticas hacia la familia son escasas pues son ellas las principales prestadoras de recursos, como apoyo a un Estado del Bienestar débil y escasamente articulado en políticas integrales. No serán las asociaciones benéficas o el mercado, como en el modelo liberal, o un Estado social mucho mas extendido sino que son las familias las sustentadoras del ámbito social. Claramente España forma parte de este tipo de Estado. La familia, por tanto, tal y como hemos señalado, no sería apoyada por el Estado si no que contribuiría a la paz social mediante apoyos allí donde la acción pública por ineficaz o por escasez de recursos no llega. Frente al modelo nórdico (gasto público directo a la familia) nuestro sistema apuesta por mínimos exentos, deducciones específicas, etc. (Villota, 2004).

Poco a poco el Estado ha sido consciente de la necesidad de apoyo a las familias pero han sido políticas escasas, descoordinadas y con desigual efecto. En las dos últimas legislaturas (2004-2008 y 2008-2012) el gobierno de Rodríguez Zapatero ha impulsado nuevas e importantes leyes en el ámbito familiar, entre las que cabe destacar:

- Ley $3 / 2007$, de 22 de marzo para la igualdad efectiva de mujeres y hombres.

- Ley 39/2006, de 14 de diciembre, de Promoción de la Autonomía Personal y Atención a las personas en situación de dependencia.

- Modificación en 2007 de la Ley General de la Seguridad Social (1/1994, 20 de junio) a través de la cual:

- Se aumentan las ayudas económicas a las familias 
- Aparece el "cheque bebé", una prestación universal de $2.500 €$ por nacimiento independientemente de las condiciones económicas de la familia y del número de hijos e hijas que se tengan ${ }^{3}$.

- Se incluyen medidas para mejorar la conciliación de la vida laboral y familiar.

- Se aumenta el permiso de paternidad

- Se concretan prestaciones específicas para familias numerosas, familias monoparentales y madres con discapacidad

Estas acciones han tenido, como decíamos, desigual acogida y no todas ellas pueden considerarse políticas sociales en sentido estricto. Aunque todas ellas han contribuido de alguna manera a visibilizar el trabajo de cuidados y la acción de la familia, especialmente de las mujeres, en el ámbito social en España, amén de representar un significativo avance en cuanto a políticas de protección de la familia, resultan claramente insuficientes.

Sin embargo, junto al hecho de que las medidas son escasas, que surgen en un contexto de crisis económica en Europa y Estados Unidos, son de destacar la impronta de las mismas. $Y$ todo ello por la necesidad de fomentar la natalidad, en un país con una tasa de nacimientos de 1,38, muy por debajo de la tasa de reposición necesaria.

Ya desde antes del año 2000 los distintos organismos internacionales ponían de manifiesto la perentoria, incluso urgente necesidad, de que España impulsará medidas de fomento de la natalidad, lo cual fue escuchado, debatido pero no se tradujo en medidas reales y efectivas.

\section{Nuevos modelos de familia. Familia monoparental o monomarental.}

A pesar de la importancia de la familia, lo cierto es que en los últimos 15 años la familia tradicional, formada por una pareja heterosexual casada, con o sin descendencia, ha dejado paso a nuevos modelos de familia. Claramente estamos asistiendo a un cambio social que ha tenido su base en la esfera privada de las personas, relacionada con sus actitudes, con sus hábitos y con su modo de entender la convivencia. Así, la afectividad no condicionada por una opción sexual, la adjudicación de nuevos roles en la pareja o el interés de mantener una relación sentimental sin imposiciones de carácter legal ha favorecido decididamente a ampliar el concepto de familia, más allá de la unión matrimonial (Fernández, 2004).

De este modo, los estudios sobre los nuevos modelos familiares, por lo general, se centran en las nuevas formas de convivencia al margen del modelo nuclear. Asimismo, cabe señalar que la familia no sólo es un grupo de personas que mantienen lazos consanguíneos o afines y que viven juntas durante un determinado intervalo de su vida, sino que también es una institución social que despliega una determinada ideología en la socialización de sus miembros (Hernández, 2009). Por ello, a pesar de los grandes cambios

\footnotetext{
${ }^{3}$ Medida suprimida partir del 1 de enero de 2011 con el objetivo, según el gobierno, de reducir el déficit.
} 
que ha venido experimentando la institución familiar, ésta sigue constituyendo un elemento fundamental en la organización de la vida social.

Si bien, como señala Mora (2004) no hay un consenso para aceptar ciertas formas de convivencia en pareja, para conceptualizarlas o definirlas, para considerarlas como transitorias o estables, o para explicar los efectos de la incorporación de las mujeres al trabajo remunerado y sus consecuencias para el grupo familiar, si hay un claro acuerdo en cuanto la familia como institución, lejos de encontrarse en vías de desaparición, paulatinamente, ha ido transformándose y tomando una posición de centralidad para la comprensión de los fenómenos sociales.

Evidentemente no es fácil definir un concepto de familia generalizado, capaz de incluir elementos tan específicos como la monoparentalidad, la proliferación de las parejas de hecho, parejas homosexuales, las formas de vida en común sin mediación de lazos de consanguinidad o incluso de relaciones afectivas, 0 la extensión de las familias unipersonales (Ruiz-Huerta, 2004).

No obstante, a pesar de las discrepancias entre los estudiosos de las familias españolas a la hora de conceptualizar los nuevos modelos familiares, podríamos decir que en la actualidad los modelos más significativos son:

- La familia conyugal o nuclear, compuesta por una pareja heterosexual, casada, con o sin descendencia.

- La familia recompuesta, compuesta por parejas que al menos uno de sus miembros proviene de una unión anterior, a los que se le suma, si los hubiere, los hijos e hijas de la primera relación más los propios de la nueva unión.

- La familia monoparental compuesta por un solo progenitor, mayoritariamente la madre y sus hijos e hijas.

Como ya hemos comentado anteriormente, entre los cambios más significativos experimentados en los últimos años en España respecto a los modelos familiares, nos encontramos con un importante aumento de familias monoparentales, aunque deberíamos decir monomarentales por estar encabezadas fundamentalmente por mujeres. Este fenómeno tiene lugar en un proceso de creciente pluralización de las estrategias de convivencia en los países occidentales (Rodríguez, 2003). A pesar de que la monoparentalidad no se trata de una manifestación reciente, sus problemáticas actuales y sus implicaciones sociales son, en muchos aspectos, radicalmente nueva (Flaquer, Almeda y Navarro, 2006). Por ello, a nuestro entender necesitan una especial atención.

En la década de los ochenta, coincidiendo con un momento de cambio y emancipación social de la mujer y el incremento de divorcios, surge la monoparentalidad como fenómeno sociológico, lo que hizo que este tipo de familias fuesen objeto de estudio y atención por parte de los poderes públicos. Nos encontramos ante una realidad social, familiar y personal fruto del cambio y conflicto social. Es un fenómeno de ámbito urbano que, si bien comenzó siendo temporal, actualmente se considera estable y económicamente viable. Es un nuevo modelo de familia que va en progresivo aumento, ciñéndose básicamente en torno a las madres divorciadas, separadas y solteras, con un incremento significativo en la última década (Mora, 2004). 
Distintos autores han identificado la monoparentalidad como un grupo de riesgo, asociándola con la incidencia y prevalencia de determinados problemas sociales, sin embargo, las familias monoparentales no conforman un grupo homogéneo, sino que con esta clasificación se engloba numerosas y diversas realidades sociales, por lo tanto, la estructura familiar no es la única variable importante para comprender su situación. Factores como la clase social, el origen, la edad, el entorno, las oportunidades educativas y económicas o sus circunstancias vitales, son igualmente significativos. Por ejemplo, en cuanto al origen hay familias monoparentales que parten de la maternidad, biológica 0 adoptiva, en solitario, por viudedad, o bien por separación o divorcio. En función de cada una de las mencionadas circunstancias se configuran distintos puntos de partida y distintas trayectorias vitales, que propician un desigual acceso a las ayudas y beneficios sociales (Morgado, González y Jiménez, 2003)

El hecho de que situaciones tan diversas se engloben dentro de un solo concepto de monoparentalidad, ha llevado a muchos autores a cuestionar la idoneidad de este concepto como categoría unitaria. Siguiendo a Barrón (2002), la consideración de dichos criterios puede incluso llevar a cuestionar la utilidad analítica y teórica de este único concepto para englobar realidades tan diversas. Por ello, cada vez son más los autores que señalan los desaciertos y limitaciones al generalizar el concepto de familia monoparental.

Existen modos alternativos de abordar la monoparentalidad desde un punto de vista conceptual y sociológico La construcción de tipologías y un examen detallado de los ejes que las fundamentan podrían suponer una aproximación efectiva. A diferencia de las definiciones, las tipologías permiten un acercamiento menos reduccionista y flexible y -más importante aún-posibilita contemplar la diversidad de situaciones y procesos monoparentales como paso previo y necesario para el estudio de cualquier variante o faceta de la monoparentalidad que se pretenda estudiar con mayor profundidad (Barrón, 2002).

En definitiva, el concepto de monoparentalidad tiene un origen sociológico y comprende una diversidad de situaciones en función de las causas que la originan así como como de los distintos proyectos de convivencia que presentan. Cabe señalar que en los últimos años se está produciendo un considerable aumento de formas voluntarias de monoparentalidad, como es el caso de las mujeres sin pareja que recurren a la adopción o a las técnicas de reproducción asistida (que en España son un tercio de las solicitantes) (VVAA, 2010).

\section{Las políticas públicas de apoyo a las familias}

Es obvio que la familia desempeña múltiples funciones sociales y por tanto merece una protección específica, y así lo reconocen diversos instrumentos internacionales como la Declaración Universal de Derechos Humanos y la Carta Social Europea, y nacionales como el artículo 39 de la C.E. de 1970 el cual establece que: 
"1. los poderes públicos aseguran la protección social, económica y jurídica de la familia.

2. Los poderes públicos aseguran, asimismo, la protección integral de los hijos, iguales éstos ante la ley con independencia de su filiación, y de las madres, cualquiera que sea su estado civil (...)

3. Los padres deben prestar asistencia de todo orden a los hijos habidos dentro o fuera del matrimonio durante su minoría de edad y en los demás casos en que legalmente proceda

4. Los niños gozarán de la protección prevista en los acuerdos internacionales que velan por sus derechos".

Últimamente prolifera el discurso desde los poderes públicos a la hora de considerar las ayudas a las familias como una de las partes más significativas de las políticas sociales, aunque con frecuencia, tras la perspectiva de familia se enmarca una concepción familiar que tiende a ser bastante tradicional y en consecuencia poco generalizable. Como hemos visto hasta ahora, las familias tradicionales van perdiendo fuerza para dar paso a nuevos modelos familiares con una gran diversidad de formas de convivencia.

Es obvio que se está produciendo en la actualidad un cambio bastante significativo al respecto. Existe una clara diferenciación entre sexualidad y reproducción, y los avances en la genética y en la reproducción asistida ofrecen cada día nuevas y variadas experiencias de cómo ser padre o madre, o ambas cosas a la vez. Asimismo, la familia ha ido perdiendo su significación de unidad económica de destino, en la medida que la mujer ha ido adquiriendo mayor autonomía desde su acceso a la formación y al mercado de trabajo.

En consecuencia, hoy día la familia es una opción de elección libre, una asociación de personas, a la que cada una llega con sus planes individuales, con sus propios intereses y experiencias, y cuya estabilidad está sometida a una gran diversidad de riesgos, limitaciones y presiones. Se necesitan muchos más esfuerzos que antes para mantener unos lazos que respeten las biografías de cada quien y que al mismo tiempo den valor a la unión, lo que dificulta mantener un equilibrio coherente al respecto.

A tenor de ello, teniendo en cuenta que el modelo tradicional se va debilitando y por tanto el "chollo familia-mujer cuidalotodo" (Subirats, 2004) tiende a desaparecer, es urgente invertir en recursos públicos de apoyo a las familias. No obstante, los cambios y transformaciones que se están produciendo en la esfera productiva, social y familiar, se producen en un contexto en el que los poderes públicos no están en su mejor momento, lo que supone para las administraciones públicas una dificultad a la hora de dar respuestas adecuadas a las distintas necesidades y demandas.

De este modo, en un contexto de mercado globalizado, de fragmentación institucional, y de gestión privada de servicios públicos, las políticas públicas, se han ido volviendo poco operativas, poco capaces de incorporar las nuevas demandas, las nuevas sensibilidades o tienen una posición débil ante nuevos problemas.

Sin embargo, a pesar de que hoy día nos encontramos ante unas las demandas cada vez más heterogéneas que deben abordarse desde formas de 
gestión flexibles y desburocratizadas, la vida familiar, sea cual sea la fórmula para definirla, sigue siendo un patrón de referencia obligado cuando hablamos de determinadas políticas de protección social o de desgravación fiscal, o cuando oímos hablar de las empresas de ayuda familiar o de las organizaciones de voluntariado que atienden algunas necesidades de las familias, especialmente en relación con las personas dependientes. Según Ruiz- Huerta (2004) una primera consideración sobre las ayudas a las familias nos lleva inevitablemente al ámbito del sector público, en donde podemos constatar las enormes las carencias de políticas públicas de apoyo a la familia en nuestro país. En este sentido, tanto las ayudas económicas como de servicios a las familias, muestran unos niveles inferiores a las de otros países europeos. Cabe señalar que las políticas de protección a la familia se enmarcan dentro de las políticas de protección social, las cuales según la clasificación de la Unión Europea abarcan: asistencia sanitaria, prestaciones de invalidez, pensiones de jubilación, pensiones de viudedad y orfandad, prestaciones familiares, prestaciones por paro, subvenciones a la vivienda y ayudas para evitar la exclusión social.

Siguiendo la Guía de Ayudas Sociales para la Familia 2010, de entre las principales políticas que se están llevando a cabo a este respecto podemos destacar:

a) Prestaciones familiares de la Seguridad Social, permisos parentales y excedencias $^{4}$

b) Ayudas en materia de empleo: Prestaciones por desempleo a nivel asistencial y programa de fomento del empleo

c) Beneficios fiscales por hijo a cargo en el impuesto sobre la renta de las personas físicas (I.R.P.F.): Deducciones estatales y deducciones autonómicas. En Andalucía y Asturias las hay para familias monoparentales.

d) Ayudas sociales a familias numerosas

e) Prestaciones sociales del Sistema Público de Servicios Sociales a las familias

f) Ayudas para para familias con personas en situación de dependencia

g) Ayudas en caso de impago de pensiones de alimentos en situaciones de separación o divorcio.

\footnotetext{
${ }^{4}$ Éstas englobarían las siguientes ayudas y prestaciones:

-Las prestaciones económicas en un único pago por nacimiento o adopción de hijos.

- Las prestaciones económicas en un único pago por nacimiento o adopción de hijos en los supuestos de familias numerosas, monoparentales y madres con discapacidad; por parto 0 adopción múltiples.

- La asignación económica por hijo o acogido menor de 18 años, o hijo con discapacidad

- El subsidio por maternidad, tanto en su modalidad contributiva como no contributiva, el subsidio especial por parto, adopción o acogimiento múltiple, los subsidios por paternidad, así como por riesgo durante el embarazo y riesgo durante la lactancia natural

- La prestación no económica por excedencia para el cuidado de cada hijo, de menor acogido o de otros.

Las prestaciones familiares de la Seguridad Social enumeradas en los apartados 1 y 2 , y el subsidio por maternidad no contributivo, son de modalidad no contributiva. No obstante, los subsidios por maternidad (incluyendo el subsidio especial por parto, adopción o acogimiento múltiples), paternidad, riesgo durante el embarazo y riesgo durante la lactancia natural, así como la prestación no económica por excedencia, son de modalidad contributiva, es decir, se conceden a los trabajadores incluidos en determinados regímenes del sistema de la Seguridad Social
} 
h) Servicios para cuidados de hijos menores de 3 años

i) Ayudas en materia de vivienda.

De este modo, la protección social a las familias se articula básicamente alrededor de dos grandes ejes: La Compensación Pública de Cargas Familiares y la facilitación de la conciliación de la vida familiar y la vida laboral (Meil Landwerlin, 2010).

Los dispositivos principales a través de los que se lleva a cabo la Compensación Pública de las Cargas Familiares son (Ministerio de Trabajo e inmigración, 2011):

a) Prestación económica por hijo o menor acogido a cargo. Asignación económica por cada hijo a cargo, menor de 18 años o mayor afectado de una discapacidad, cualquiera que sea su filiación, así como por los menores acogidos en acogimiento familiar, permanente o preadoptivo, siempre que no se supere el límite de ingresos establecido. Para 2011 la cuantía de la asignación económica por hijo o menor acogido a cargo menor de 18 años no discapacitado será, en cómputo anual, de 291,00 €.

b) Prestación económica por nacimiento, adopción o acogida familiar, las cuales consisten en:

1. Prestación por parto múltiple, cuyo importe se calcula, multiplicando por un determinado número de veces el SMI en función del número de hijos.

\begin{tabular}{|c|c|c|}
\hline № de hijos nacidos & № de veces del SMI & Importe para 2011 \\
\hline 2 & 4 & $2.565,60 €$ \\
\hline 3 & 8 & $5.131,20 €$ \\
\hline 4 y más & 12 & $7.696,80 €$ \\
\hline
\end{tabular}

Fuente: web Seguridad Social 2011

2. Por nacimiento de tercer o sucesivos, se abona en un pago único, cuya cuantía asciende a 450,76 euros, siempre que los ingresos del beneficiario no rebasen el límite establecido.

3. Y el fugaz "cheque bebé", con una vigencia de apenas 3 años (20072010) consistente en una aportación única de $2.500 €$ por nacimiento, independientemente del número de hijos y los ingresos familiares.

4. En supuestos de familias numerosas, monoparentales y en los casos de madres discapacitadas $1.000,00 €$. En familias numerosas o que, con tal motivo, adquieran dicha condición, en familias monoparentales y en los casos de madres que padezcan una discapacidad igual o superior al $65 \%$, siempre que no se supere un determinado nivel de ingresos. No se reconoce esta prestación en los supuestos de acogimiento familiar.

c) Prestación económica por hijos o menores acogidos a cargo: 
1. Menores de 18 años no discapacitados 291,00 euros anuales $(24,25$ euros mensuales), cuando los ingresos del beneficiario no rebasen el límite establecido de $11.264,01$ euros anuales más un $15 \%$ por cada hijo o menor acogido a cargo a partir del segundo. Si se trata de familias numerosas, el límite será de 16.953,05 euros, en los supuestos en que concurran 3 hijos a cargo, incrementándose en 2.745,93 euros por cada hijo a cargo a partir del cuarto, éste incluido.

2. Hijos o menores acogidos menores de 18 años con una discapacidad igual o superior al $33 \%$. La prestación es de 1000,00 euros anuales por hijo (250,00 euros trimestrales). No se exige en estos casos límite de recursos económicos al tratarse de un discapacitado.

3. Hijos mayores de 18 años y con una discapacidad igual o superior al $65 \%, 4.171,20$ euros anuales por hijo (347,60 euros mensuales). No se exige en estos casos límite de recursos económicos al tratarse de un discapacitado.

4. Hijos mayores de 18 años y con una discapacidad igual o superior al $75 \%$ que necesiten de la ayuda de otra persona para realizar las actividades de la vida diaria, 6.256,80 euros anuales por hijo (521,40 euros mensuales). No se exige en estos casos límite de recursos económicos al tratarse de un discapacitado.

d) Prestación económica por nacimiento o adopción de hijo, 2.500 euros de deducción en el IRPF o prestación no contributiva de la Seguridad Social si no trabaja o no obtiene rentas sujetas a retención del IRPF o cuando se trate de contribuyente al que le resulten aplicables las normas forales de Navarra o del País Vasco en el IRPF. Esta prestación es compatible con la percepción de las demás prestaciones familiares de la Seguridad Social.

\section{e) Deducciones fiscales del Impuesto sobre la Renta}

1. Deducción por maternidad exclusivamente para madres trabajadoras con hijos menores de 3 años que estén dadas de alta en algún régimen de la Seguridad Social. La deducción consiste en 1.200,00 € anuales por cada hijo menor de 3 años, siempre que las cotizaciones y cuotas totales a la Seguridad Social y Mutualidades superen dicha cantidad, en caso de que sea menor, la deducción será igual al importe total devengado por este motivo. Deducción de la base en concepto de mínimo vital por descendientes a cargo menores de 25 años (o cualquiera que sea su edad cuando el descendiente a cargo sea discapacitado con un grado de minusvalía igual o superior al 33\%) y que no tengan rentas anuales superiores a 8.000 euros, por importe de 1.836 el primero, 2.040 el segundo, 3.672 el tercero y 4.182 el cuarto y siguientes.

2. Incremento del mínimo vital por descendientes a cargo menores de 3 años de 2.244 euros anuales o mayores de dicha edad en caso de adopción o acogimiento por un período de 3 años. 
3. Incremento del mínimo vital por descendientes a cargo con minusvalía de 2.316 si el grado de minusvalía se encuentra entre el 33 y el $65 \%$ y de 7.038 si es superior al $65 \%$.

4. Incremento del mínimo vital individual en caso de monoparentalidad de

2.150 euros anuales.

f) Otras prestaciones:

Fondo de garantía de las pensiones por alimentos en casos de divorcio o separación legal, cuando el cónyuge obligado a pagarlas no lo hace, por importe máximo de 100 euros mensuales.

Debido a la insuficiencia de las cuantías de las prestaciones a nivel estatal, algunas Comunidades Autónomas las mejoran o establecen condiciones menos restrictivas para su aplicación, lo que conlleva una falta de homogeneidad entre las distintas comunidades. Por ejemplo, sólo las comunidades de Andalucía, Cantabria, Castilla-León, Castilla-La Mancha, Cataluña, Galicia y Navarra contemplan la prestación por hijo a cargo. En cuanto a ayudas por nacimiento o adopción son las comunidades de CastillaLeón, Madrid y País Vasco las únicas que las contemplan, el resto se ciñen a actuaciones llevadas a cabo a través del sistema tributario o mediante la aplicación de descuentos en algunos servicios públicos.

No obstante, dado que desde 1997 las Comunidades Autónomas (CCAA) participan en el IRPF, las mismas adquieren la capacidad de realizar modificaciones como añadir nuevas deducciones. Esto unido a la transferencia realizada por el Estado de competencias en materia de Política social, hace necesario conocer individualizamente qué acciones realiza cada CCAA. Tal y como señalan (Cubel y De Gispert, 2009: 13): “Mientras que la modificación de la tarifa complementaria sólo se ha llevado a cabo por parte de la comunidad de Madrid para el ejercicio de 2007, la introducción de deducciones específicas ha sido una práctica generalizada en todas las CCAA, principalmente de naturaleza familiar y relativa a la vivienda habitual. Es necesario señalar que las deducciones son muy variadas (...), las deducciones autonómicas de naturaleza familiar reguladas en 2007 hacen referencia principalmente a las siguientes circunstancias...: nacimiento o adopción de hijos, acogida de menores o de mayores de 65 años, cuidado de familiares, gastos de guardería, discapacidad de los contribuyentes o de los familiares, familias monoparentales y familias numerosas. En concreto, en el caso de Cataluña está vigente una deducción por nacimiento o adopción de $300 €$ por hijo en declaración conjunta de los progenitores y de $150 €$ en declaración individual de cada uno de ellos; así como una deducción para los contribuyentes en situación de viudedad de $150 €$ o de $300 €$ si tiene uno o más descendientes".

Respecto a la facilitación de la conciliación de la vida familiar y la vida laboral podríamos señalar que este objetivo, si bien pasa a formar parte de las políticas familiares, no se ha iniciado como tal, sino como una parte de las políticas de igualdad de género en el marco de los planes de igualdad de oportunidades entre mujeres y hombres (Meil Landwerlin, 2010). De este modo, las actuaciones más significativas llevadas a cabo son los permisos de 
maternidad y de paternidad ${ }^{5}$, así como los permisos paternos destinados a hacerse cargo de los hijos u otros familiares dependientes, en cierto sentido para procurar eliminar las discriminaciones derivadas de la maternidad y posteriormente como una vía para promover la igualdad de los sexos fomentando la implicación de los padres varones en las políticas de permisos parentales. En este sentido, con la aprobación del Real Decreto 1251/2001, de 16 de noviembre, por el que se regulan las prestaciones económicas del sistema de la Seguridad Social por maternidad y riesgo durante el embarazo, se incorporó como principales novedades la posibilidad de disfrutar el permiso por maternidad en régimen de tiempo parcial, es decir, haciéndolo compatible con el mantenimiento de la actividad laboral con reducción de jornada y se flexibilizó el disfrute del permiso por maternidad en los casos de parto prematuro u hospitalización tras el parto, a efectos de poder iniciar el cómputo de ese periodo a partir del alta hospitalaria, atendiendo las demandas en este sentido de los colectivos afectados (Marina, 2004).

Asimismo, otro de los aspectos que se han abordado en materia de conciliación, y que se configura como uno de los recursos fundamentales para facilitarla, es la mejora de la oferta de servicios de atención a menores de tres años (ludotecas, guarderías, etc...). Aunque la misma es todavía insuficiente, se ha venido produciendo en los últimos años un importante un incremento de las dotaciones para programas de atención a la primera infancia desde la Administración Central, con la colaboración con las Comunidades Autónomas y/o Corporaciones Locales.

\section{4. ¿Políticas para familias monoparentales?}

En primer lugar cabe señalar que no existen prestaciones o ayudas específicas para las familias monomarentales, en general. Por tanto, éstas perciben las prestaciones o ayudas en el mismo grado y bajo los mismos supuestos que el resto. Como bien señala Jociles et all (2008) esto es apreciable en las distintas formas que suele adoptar la protección social en nuestro país. De este modo, en relación a las medidas para la conciliación de la vida laboral y familiar ${ }^{6}$, la Seguridad Social articula fundamentalmente permisos laborales, como son las bajas por maternidad, los permisos por motivos familiares urgentes, o las excedencias para el cuidado de hijos menores de ocho años, que son poco utilizadas por las madres/padres porque, tal como indican Fernández Cordón y Tobío (2006), no son remuneradas.

En este sentido, la conciliación de la vida laboral y el cuidado de los hijos/as, para las familias monoparentales, se presenta con más dificultades que para las familias biparentales, debido a que las mujeres al frente de un hogar monoparental, a excepción de las viudas, tienen tasas de empleo superiores a las madres que viven en hogares biparentales. Evidentemente este no es un

\footnotetext{
${ }^{5}$ Descanso laboral concedido, en caso de parto, adopción o acogimiento familiar (permanente o preadoptivo), a las personas trabajadoras que cotizan a la Seguridad Social o que se encuentran en situación asimilada. En España es obligatorio para beneficiarse de esta prestación haber cotizado 180 días.

${ }^{6}$ Ley 39/1999, de 5 de noviembre
} 
problema exclusivo de las familias monoparentales, pero también es cierto que el problema se incrementa considerablemente en cuanto la mujer que encabeza un hogar monoparental no puede compartir la realización de las tareas domésticas con su pareja, ni los gastos ya que solo cuenta con un único ingreso para hacer frente a la economía familiar. De este modo, para las familias monoparentales, el empleo no sólo se presenta como una cuestión prioritaria sino que plantea retos específicos a las mismas.

Según establece la Ley 3/2007 de 22 de marzo de igualdad efectiva entre mujeres y hombres, las empresas deben facilitar a su personal el poder conciliar su vida laboral con su vida familiar y personal, con medidas que pueden ir desde horario flexible, reducción de jornada, teletrabajo, bancos del tiempo, entre otras medidas que serán fundamentales en el caso de mujeres al frente de un hogar monoparental.

No obstante, las medidas que favorecen la conciliación de la vida laboral y familiar no deben ceñirse únicamente a los permisos u horarios laborales, otras alternativas son la creación de más servicios de educación infantil, en especial, para la franja de edad comprendida de 0 a 3 años. Si bien como hemos señalado con anterioridad esta medida se va incrementando con los años, aún queda mucho camino que recorrer, y no solo en cuestión de aumento de plazas, sino que la monoparentalidad sea un criterio preferente de acceso a ella.

Sin embargo, y más allá de ello, las acciones y políticas discriminatorias surgen de medidas incongruentes. Así dentro de las propias familias monoparentales, las mismas no obtienen la categoría de familias numerosas si tienen dos hijos, pero sí los son si se trata de viudos/as. En 2007 las familias de viudos y viudas con dos hijos fueron consideradas como familias numerosas. Desde ese momento, las posteriores leyes de presupuestos establecían una disposición adicional para que se realizaran modificaciones legales para que esa medida se extendiese al resto de las familias monoparentales y no se viesen discriminadas, sin embargo, hasta la actualidad eso no ha sido así. En ese aspecto, por tanto, las familias monoparentales sufren una doble discriminación frente a las familias conformadas por viudos/as y las biparentales con tres hijos, que son consideradas familias numerosas, ya que ellos se enfrentan a hijo y medio por progenitor mientras que las monoparentales a dos hijos por progenitor.

Ahondando en dicha discriminación, De Villota (2004), a través de su estudio sobre presupuestos de género, realiza un recorrido por los distintos sistemas impositivos de Europa, centrándose en el caso español. Aunque el objetivo del estudio no son las familias monoparentales en el mismo se incide en la discriminación existente hacia dichos modelos de familia y sostiene la necesidad de abogar por la tributación individual independientemente del estado civil de la persona y sus circunstancias familiares pues el actual sistema favorece a las familias biparentales y tradicionales. Incluso los defensores de la tributación familiar (entendida ésta como la conformada por padre y madre) no llegan a un acuerdo sobre qué tratamiento fiscal darles a las otras familias.

En cuanto al ámbito tributario, según Villota (2010), en España, desde 1999 se viene penalizando a las familias monoparentales frente a las biparentales al establecer diferencias por cuestión de estado civil. La diferencia radica, de 
acuerdo con la derogada Ley 18/1991, en que a las familias monoparentales se aplicaban para calcular la cuota del impuesto la misma escala de tributación que las familias biparentales, mientras que, actualmente, con la Ley 40/1998 la igualdad de trato se rompe al aplicar una reducción en concepto de "mínimo personal" en su base imponible de cuantía inferior a la legalmente establecida para las familias biparentales. Siguiendo a la autora, "este cambio de criterio supone un agravio comparativo para las cerca de 300.000 familias monoparentales afectadas, ya que no pueden aplicarse la misma reducción impositiva que las familias biparentales... (Ello va) en contra de todas las recomendaciones procedentes de la Unión Europea, las familias monoparentales quedan sujetas a mayor tributación que las familias biparentales. La diferencia es de un $14 \%$ y $8 \%$ de penalización cuando los ingresos se sitúan en torno a $21.000 €$ y $30.000 €$ respectivamente. ... se percibe la discriminación padecida por las familias monoparentales con el IRPF actual. Y esto es así, como consecuencia de la pérdida real de capacidad adquisitiva que sufren al quedar sujetas a un mayor gravamen. Esta discriminación se efectúa a través de dos mecanismos distintos. El primero, mediante los mínimos personales y familiares $y$, el segundo, por la transformación sufrida por las deducciones personales y familiares de la cuota en reducciones de la base".

Respecto a la discriminación fiscal, como señala la misma autora en otro estudio (Villota, 2003): "El IRPF las familias biparentales disfrutan de un mínimo exento de 6.800 euros frente a los 5.550 euros de las familias monoparentales (...) que se traduce en una reducción del impuesto a pagar que oscila entre 0 euros y 562,50 euros, dependiendo de la renta total del/de la contribuyente y que supone un agravio comparativo para este tipo de familia. Las CCAA podrían crear una deducción autonómica en favor a las familias monoparentales para compensar parcial o totalmente el exceso de tributación padecido. El mecanismo de tal discriminación lo genera (...) el que las familias biparentales dispongan de una reducción en su base imponible de 3.400 euros frente a sólo 2.150 euros para las monoparentales".

\section{Conclusiones}

Las políticas públicas en escasas ocasiones son anticipatorias a la problemática social detectada. En este caso es obvio que no se han establecido políticas para evitar la desigualdad de trato de las madres solas por elección y que solamente una política reactiva podrá solucionar el problema. Para ello nada mejor que la presión por parte de las asociaciones de familias monoparentales. En ese sentido, a través del manifiesto leído durante las Jornadas de la Federación de Asociaciones de Madres Solas (FAMS), celebradas en julio de 2011, firmado por cinco entidades que han formado una Red de Familias Monoparentales, se reivindica fundamentalmente, la creación de una Ley de Familias Monoparentales con el fin de erradicar las diferencias existentes entre las comunidades autónomas y que contemple "la diversidad que la monoparentalidad ofrece". De este modo, según aseguran las organizaciones, "se daría contenido a los vacíos legales que existen en la 
actualidad". Asimismo, entre las reivindicaciones de la Red, además citada Ley de Familias Monoparentales, destaca la "igualdad de oportunidades, de derechos y deberes que el resto de familias para mejorar la calidad de vida $y$ dejar de vincular la monoparentalidad a la exclusión social" (FAMS, 2011).

Cabe señalar que en nuestro país el 10 por ciento de las familias son monoparentales, y el 87 por ciento de éstas encabezadas por mujeres, datos que revelan el clarísimo sesgo de género que presenta esta modalidad familiar. Sin embargo, las políticas que hasta hoy están destinadas a las familias monoparentales se muestran claramente insuficientes pues no dan respuesta a las necesidades y demandas de este colectivo. Asimismo, las Comunidades Autónomas diseñan distintos planes que generan desigualdades entre ellas en cuestión de cobertura social y oportunidades.

Del mismo modo, se hace necesario llevar a cabo investigaciones para obtener datos cuantitativos y cualitativos sobre la realidad actual, así como la elaboración de políticas fiscales no discriminatorias contemplando la perspectiva de género y que se implanten medidas eficaces en materia de formación, empleo, educación, conciliación, vivienda, permisos, etc., que favorezcan la inclusión.

Como hemos visto hasta ahora, la monoparentalidad puede deberse a diversas causas como son las separaciones o divorcios, la viudedad, sin olvidar, incluso cabe subrayar, el progresivo aumento de mujeres que deciden emprender un proyecto de maternidad en solitario por libre elección. Por ello hay que reconocer la coexistencia de diversos modelos familiares dentro de la monoparentalidad, así como es fundamental realizar una revisión de las políticas familiares existentes hasta hora y replantearlas incorporando la perspectiva de género, de modo que se adecuen a las nuevas realidades y den respuesta a las necesidades específicas de estos modelos familiares.

\section{Bibliografía}

- (2002) BARRÓN, S. "Familias monoparentales: un ejercicio de clarificación conceptual y sociológica" Revista del Ministerio de Trabajo y Asuntos Sociales, Madrid, nำ 40

- (2009) CUBEL, M y GISPERT, C La Protección de la Familia en España: aún lejos de Europa. Ed. Cátedra de Políticas de Familia UCM-AFA, Valencia. Disponible www.unav.es/icf/main/top/.../AccionFamiliar_ProteccionFamilia.pdf

en

- (2004) DE VILLOTA, P. Economía y género: macroeconomía, política fiscal y liberalización. Análisis de su impacto sobre las mujeres. Ed. Icaria, Barcelona.

- (2010) DE VILLOTA, P. Análisis del retroceso desde la perspectiva de género en la política fiscal española. Disponible en http://ebookbrowse.com/paloma-villota-comunicacion-pdf-d116472328 
- (2000) ESPING-ANDERSEN, G. Fundamentos sociales de las economías postindustriales. Ed. Ariel, Barcelona.

- (2011) FEDERACIÓN DE ASOCIACIONES DE MADRES SOLTERAS (FAMS). Jornada 'Mi situación jurídica, sin ley específica'. Disponible en http://federacionmadresolteras.org/index.php?option=com_content\&view=article \&id=105: jornadas-famsmanifiesto \&catid $=1$ :noticias-federacion\&ltemid $=91$

- (2006) FERNÁNDEZ-CORDÓN, J. A. y TOBIO, C. Andalucía: Dependencia y solidaridad en las redes familiares, Ed. IEA, Sevilla.

- (2004) FERNÁNDEZ, T. Las políticas sociales: una manera de construir "familia". Disponible en www.fad.es/sala_lectura/lICongresoFamilias_conf.pdf

- (2006) FLAQUER, L., ALMEDA, E y NAVARRO-VARAS, L. Monoparentalidad e infancia. Ed. Fundación 'La Caixa', Colección Estudios Sociales, 20, Barcelona.

- (2000) GOODIN, R., Y OTROS The Real Words of Welfare Capilalism, Cambridge University Press, Cambridge.

- (2008) JOCILES, M. I. Y OTROS. "Una reflexión crítica sobre la monoparentalidad: el caso de las madres solteras por elección". Revista Portularia. Vol. VIII. № 1, Huelva, p. 265-274.

- (2004) MARINA, A. Políticas estatales de apoyo a la familia. Disponible en www.fad.es/sala_lectura/llCongresoFamilias_conf.pdf

- (2002) KASZA, J "The Illusion of Welfare 'Regimes"'. Journal of Social Policy, 31, p. 271-287

- (2010) MARTíN, M.C y RUIZ, S. "Ley de Dependencia: una mirada con perspectiva de género". Revista Documentos de Trabajo Social no 48, p. 8498.

- (2010) MEIL LANDWERLIN, G. La protección social a las familias en España, en Jornadas familiares monoparentales. Ed. Ministerio de Trabajo e inmigración. Seguridad Social, Madrid. Disponible en https://afamo.wordpress.com/.../jornadas-madrid-2010-polticas-famili..

- (2004) MORA, G. Las Familias monoparentales. Disponible en www.fad.es/sala_lectura/IICongresoFamilias_conf.pdf

- (2003) MORGADO, B., GONZALÉZ, M.M. y JIMÉNEZ, I. "Familias monomarentales: problemas, necesidades y recursos". Revista Portularia № 3 , p.137-160 
- (2003) RODRIGUEZ, C. "Un análisis del concepto de familia monoparental a partir de una investigación sobre núcleos familiares monoparentales". Revista Papers № 69. P. 59-82

- (2004) RUíZ-HUERTA, J. Algunas consideraciones sobre las ayudas a las familias: entre la protección social y la cobertura privada. www.fad.es/sala_lectura/IICongresoFamilias_conf.pdf

- (2010) SANTISO, R. "La dialéctica entre la familia y el Estado de Bienestar". Revista Acciones e investigación social, № 10. P. 23-48.

Disponible en www.dialnet.unirioja.es/servlet/artículo?codigo=170262

- (2004) SARACENO, C. "Política social y familiar", en D. I. Kertzer y M. Barbagli (comp.), La vida familiar en el siglo XX, Ed. Paidós, Barcelona, p. 333369.

- (2004) SUBIRATS, J. Interacción entre la familia y otros actores de las políticas de bienestar. Disponible en www.fad.es/sala_lectura/IICongresoFamilias_conf.pdf

- (2010) VVAA. La revisión de la protección de las familias monoparentales por parte de la seguridad social. Disponible en

http://www.seg-social.es/prdi00/groups/public/documents/binario/146758.pdf 